\title{
Research on the Cost and Benefit of Human Capital Investment
}

\author{
Ningning Yan \\ School of Management and Economics, Jingdezhen Ceramic Institute, Jiangxi Province, China \\ Isemail2008@163.com
}

Keywords: Talent cultivation; Education investment; Cost; Benefit

\begin{abstract}
According to current situation of high number of education investment in human resources, analyzes the cost and income of education investment in human capital, best critical point and from two angles of the marginal revenue and marginal cost of education found in human capital investment, to make a reference for the education of human capital investment of individuals and families. Finally, the paper puts forward some concrete measures to promote the investment of educational human capital from the best critical point: to increase the income and reduce the cost.
\end{abstract}

\section{Introduction}

Human capital is condensed in the workers, through its ability, knowledge, technology, health and other aspects to reflect. At the same time, the formation of human capital should be realized through investment, including formal investment, informal investment, health investment, labor migration and investment. Therefore, the cultivation of talents should be realized through investment. With the development of the era of mass higher education, the state, society, family and individual are increasing their investment in human capital. So it is necessary for us to study the cost and benefit of human capital investment from the angle of Economics. China's political and economic systems are constantly deepening the reform, the industrial structure is also escalating, science and technology is also developing rapidly, in this critical period of personnel training is the top priority. The future of the country's investment will be more and more. But the more human capital investment does not mean that the human capital investment income will be greater (only when the marginal revenue is greater than the marginal cost, the more investment, the greater the revenue) [4]. The family is the main body of higher investment, therefore in the process of human capital investment decision, to rational thinking, improve their own quality, master the complete information, establish the consciousness of cost and risk awareness, so as to steadily improve the human capital investment income.

\section{Cost Analysis of Human Capital Investment}

Human capital investment mainly includes three aspects:

First of all, is the direct cost, it is to cultivate a talent, from the beginning has been affected by to jobs, the direct costs of all accepted, including individuals, families of students pay tuition fees and living expenses and study all expenses directly or indirectly related.

Second, the indirect cost. Indirect costs are divided into two aspects of economic costs and psychological aspects of pay. The cost of the economy is that in the process of personnel training, due to the acceptance and give up the other may bring the greatest benefits. When a student reaches the legal age, he or she will continue to study or work, and make an investment cost and benefit analysis. When the lower the rate of return on investment, the higher the maximum yield, the lower the chance of acceptance. On the contrary, on the big. Now due to the mismatch of universities and the labor market information in China, the gap between supply and demand caused by the phenomenon of difficult employment of college students caused part of the region especially in rural areas, the "useless", this is the expected return on investment mistakes. The psychological aspects of indirect costs include: first, the psychological cost. In the era of globalization, the higher stage of popularization. Every member of the society is under great pressure to survive, and in the process of training, the people are experiencing the pressure which the ordinary people do not have. One is the selection of personnel is very strict, they have 
to go through the layers of assessment, such as the college entrance examination, entrance, which is the opportunity of talent ability, skills assessment, and Study on the psychological quality, health personnel. In this process, they have to bear a lot of psychological pressure; two is to accept the pressure in the process, and now the state to ensure the quality of graduate students in the continuous increase in the workload of learning. Every college required quantity, period of postgraduate thesis published standards, especially doctoral students not only provides the number of published papers also provides a level of time, journal papers, theses standards and external audit and so on, which makes many students feel the pressure. Two is the emotional cost. Before continuing to measure the costs and benefits of investment, many people have to consider the reality of the problem as well as marital problems. In today's society, the older men left $3 \mathrm{~S}$ lady encountered with many times. Because of the busy work and pressure, a lot of people have sacrificed their entertainment, social communication time, the resulting emotional problems is also the value of the loss of talent growth. Three is the cost of time. Talent continues to grow as it continues to grow. According to China's current stage of the status quo, doctoral graduates are at least 28 years old. One of the best years of life in the boring study, research, which is a huge loss of time.

Finally, the risk cost. A person who receives a good return may not be able to get the same value or higher value. Nowadays, the phenomenon of College Students' employment is widespread in our country. A person starts until graduation from the acceptance, during a period of economic cost, opportunity cost, time cost is difficult to calculate, so the development of university after graduation has become the crucial factor of balance or surplus.

In view of the large amount of investment in human capital investment, we can analyze the rationality of human capital investment, the income and the best human capital investment critical point. The marginal cost of human capital investment refers to the amount of investment per unit increase, the total increase in the cost of investment. When the unit investment increases, the total cost of investment will increase.

\section{Analysis of the Income of Human Capital Investment}

The income of human capital investment can be divided into two kinds: Economic and non economic benefits. Economic benefits include the following three aspects:

(1) The high level of investment in general people can get a better job or position, resulting in higher economic benefits. The research shows that the degree of individual is proportional to the economic income of individuals. In addition, a higher degree of acceptance of a higher level of mental ability, self-control ability, will make a reasonable plan for their financial situation. The correct and reasonable financial management and planning will bring the appropriate economic benefits.

(2) Accept the higher people generally have a strategic vision, will develop long-term planning and development. This is the most long-term basis for the development of their own health. So they pay more attention to physical exercise and investment, the body is the capital of the revolution, which will bring huge economic benefits in the future. At the same time reduce the economic costs caused by physical discomfort.

(3) With greater career choice space. A good person's own comprehensive quality is higher, easier to accept new knowledge, self-learning ability is stronger. So no matter what kind of industry, they can quickly enter the working state, for the enterprise to maximize economic benefits. At the same time, it also brings higher economic income.

When the marginal income is greater than the marginal cost, the profit is relatively large, investors will increase investment in human capital to obtain higher returns; and when the marginal revenue is less than the marginal cost, revenue is less than the cost of inputs, then investors will reduce investment, so the optimal critical point of human capital investment is when the marginal cost is equal to the marginal benefit. When the marginal cost is equal to the marginal benefit, the profit is the largest, the marginal cost and marginal benefit exist simultaneously in the whole process of the investment. 


\section{The Significance of the Optimal Critical Point of Human Capital Investment}

With the rapid development of China's economy and the increasingly fierce international competition, talent training is still an important issue in our country. How to let more people choose to invest, to contribute to the development of the country, the key is to grasp the critical point of human capital investment, make the best choice. The optimal critical point of human capital investment is marginal benefit equals marginal cost, so the way to promote human capital investment includes two aspects: increasing investment income and reducing investment cost.

Promoting human capital investment by increasing returns. When the marginal revenue is greater than the marginal cost, it will stimulate people's investment enthusiasm, so we can promote investment from the following aspects:

Establish and improve the information communication channels. At present, due to the information and employment market, employers do not match the information, resulting in college student's employment difficulties, excessive and inadequate issues. In order to promote the human capital investment must improve the information communication channels between universities and employers, strengthen market supervision and other departments to contact, timely communication of information flow, to provide complete, employment information as recipients, so that they can quickly adapt to the society, find the position, make contribution for the development of the society, forming a virtuous circle. In addition to the opening of other forms of employment channels, but also through the norms of labor contracts, protect the legitimate rights and interests of workers, increase benefits and other ways to increase security for employees. A good employment situation and job treatment can promote investment in human capital.

Establish a sound distribution system. Human capital investors are expected to be higher than the cost of inputs, so the level of wages will also affect investment. China's current distribution system is based on the distribution of work, a variety of modes of distribution coexist. The perfect way of distribution should be fair and just as much as possible, which can stimulate people's enthusiasm and initiative. Based on the theory of justice in 60s proposed by Adams, he believes that enthusiasm and motivation factors affecting not only their staff wages, but more important is the comparison between people. Each person will be based on their own work and pay the remuneration and other people who he thinks and their own labor to do the same. If you find others in the comparison is the same as his own, he thought it was fair, otherwise, it is considered unfair. People who believe that the fair will stimulate their enthusiasm for work, that unfair employees will dampen enthusiasm. Therefore, it is necessary to establish a sound distribution system, only human capital investors believe that their gains are reasonable, will promote investment in human capital.

The reform of the existing professional setup and discipline construction in Chinese colleges and universities. With the accurate grasp of the labor market and employment information, colleges and universities need to adjust their professional settings and disciplines in accordance with the needs of the market. The master of professional knowledge in order to succeed in the future career, get the maximum benefit. Especially in the era of globalization, the professional setting and discipline construction of colleges and universities should stand in an international perspective, from the international point of view to build students' training and future development.

Promoting investment by reducing the cost of human capital investment. When the cost of human capital investment is reduced, the income will be increased, which will bring investment enthusiasm. Reduce the cost of human capital investment mainly from the following aspects:

Vigorously develop the scale. From the point of view of scale economics, when the enterprise develops to a certain scale, the cost of the unit product will decrease and the profit will increase. When the size of the expansion, the cost of investment in human capital will decline. Because of the cost of running a school, the more the number of recipients, the cost to each recipient will be less, it will stimulate more people affected, thus forming a virtuous circle.

Streamlining the management of institutions. To establish and perfect internal management system, in the basis of everything someone is, everyone is responsible ", streamlining personnel change the phenomenon of redundant overlapping, more personnel than work available. The salary and welfare of 
staff in institutions or universities are also part of the cost of human capital investment, in order to reduce the cost of human capital investment should be as much as possible to streamline institutions, improve work efficiency.

Strengthen the financial management and control of institutions or universities. The institution or purchase of fixed assets is also part of the human capital investment cost, because the school teaching equipment and other fixed assets mostly belong to the state grants, at the same time, the school staff has a strong sense of responsibility of the phenomenon in the use of public facilities, which caused the waste or damage of fixed assets or institutions of colleges and universities the resulting increase in human capital investment cost. Therefore, institutions or colleges and universities must do a good job of supervision and control in this link. At the same time, institutions or colleges and universities of financial information and daily accounts should adhere to do a good job of control and accounting.

China's political and economic systems are constantly deepening the reform, the industrial structure is also escalating, science and technology is also developing rapidly, in this critical period of personnel training is the top priority. The future of the country's investment will be more and more. But the more human capital investment does not mean that the human capital investment income will be greater (only when the marginal revenue is greater than the marginal cost, the more investment, the greater the income). The family is the main body of higher investment, therefore in the process of human capital investment decision, to rational thinking, improve their own quality, master the complete information, and establish the consciousness of cost and risk awareness, so as to steadily improve the human capital investment income.

\section{Acknowledgement}

This work was supported by the research subject of teaching reform in colleges and universities of Jiangxi province (JXJG-16-11-22/ JXJG-15-11-9).

\section{References}

[1] Wei Xin. Cost benefit analysis of human capital investment: a case study in Guangxi. Productivity research, 2012 (2): 88-91.

[2] Zhao Aixue. Cost analysis of senior talent growth. Chinese adults, 2005 (9): 13-14.

[3] Xu Huijun. Management model and analysis of enterprise human capital investment. Economic Herald, 2012 (1): 68-69.

[4] Wang Hong. Investment risk analysis of enterprise human capital. China business, 2011 (31): 159-159. 